
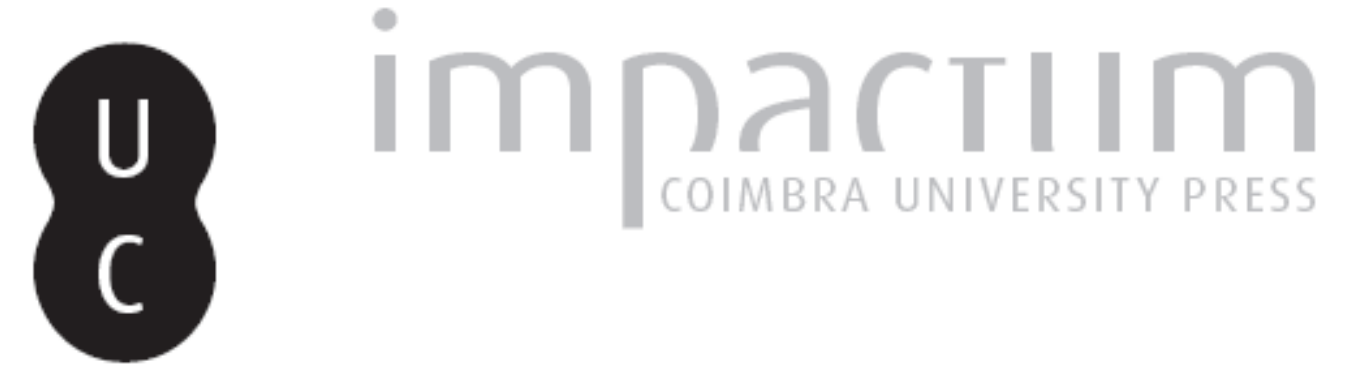

\title{
Antero e Leopardi: poetas da lua
}

\author{
Autor(es): Ragusa, Andrea
}

Publicado por: Imprensa da Universidade de Coimbra

URL persistente:

URI:http://hdl.handle.net/10316.2/42558

DOI:

DOI:https://doi.org/10.14195/0870-8584_6_14

Accessed : $\quad$ 26-Apr-2023 13:52:09

A navegação consulta e descarregamento dos títulos inseridos nas Bibliotecas Digitais UC Digitalis, UC Pombalina e UC Impactum, pressupõem a aceitação plena e sem reservas dos Termos e Condições de Uso destas Bibliotecas Digitais, disponíveis em https://digitalis.uc.pt/pt-pt/termos.

Conforme exposto nos referidos Termos e Condições de Uso, o descarregamento de títulos de acesso restrito requer uma licença válida de autorização devendo o utilizador aceder ao(s) documento(s) a partir de um endereço de IP da instituição detentora da supramencionada licença.

Ao utilizador é apenas permitido o descarregamento para uso pessoal, pelo que o emprego do(s) título(s) descarregado(s) para outro fim, designadamente comercial, carece de autorização do respetivo autor ou editor da obra.

Na medida em que todas as obras da UC Digitalis se encontram protegidas pelo Código do Direito de Autor e Direitos Conexos e demais legislação aplicável, toda a cópia, parcial ou total, deste documento, nos casos em que é legalmente admitida, deverá conter ou fazer-se acompanhar por este aviso. 


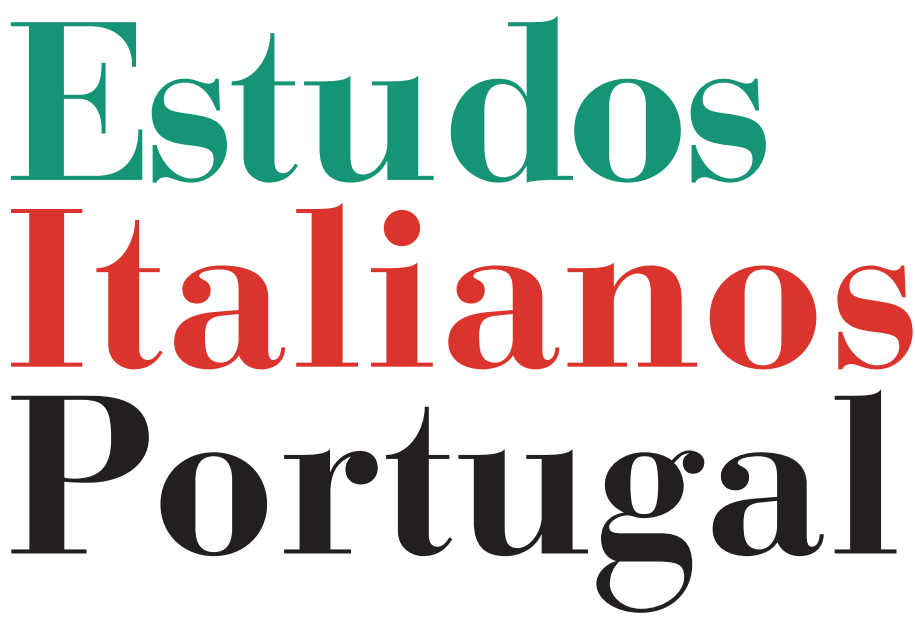

Instituto

Italiano

de Cultura

de Lisboa

Nova Série

$\mathrm{N}^{\circ} 6$ 


\title{
ANTERO E LEOPARDI, POETAS DA LUA
}

\author{
ANDREA RagusA*
}

1. Não é fácil perceber quando e como começa o interesse de Antero de Quental por Itália. Talvez tenha acontecido através da obra de Dante, ou então devido ao encontro com Feliciano de Castilho, seu primeiro mestre em Ponta Delgada e grande conhecedor das letras italianas. Com certeza a actualidade da península era bem conhecida na altura, em especial o modo como a Itália encarava, nos meados do séc. XIX, a possibilidade de pôr fim à presença de outros impérios no seu território. As vivências de Garibaldi tinham sido para Antero um grande exemplo de coesão nacional, em equilíbrio entre o peso político da Igreja Romana e a fragmentação da realidade social do país, fazendo do Risorgimento italiano um símbolo da realização dos ideais românticos.

Antero manteve, durante anos, uma amizade epistolar com o escritor siciliano Tommaso Cannizzaro (que publicara uma selecção de poemas anterianos em tradução italiana) e na própria biblioteca pessoal do poeta açoriano, como refere

*Andrea Ragusa (Turim, 1979) licenciou-se na Universidade de Turim com um trabalho final sobre o teatro de Fernando Pessoa e é Mestre em Estudos Portugueses pela Universidade Nova de Lisboa, à qual apresentou a tese Entre as dobras da solidão. Diálogos órficos entre Cesare Pavese e António Ramos Rosa. Actualmente, é investigador do Departamento de Estudos Portugueses desta Universidade, dedicando-se ao estudo da presença de Leopardi na obra e no pensamento de Antero de Quental. 
José Bruno Carreiro ${ }^{1}$, constam obras significativas das letras italianas: I dialoghi sui massimi sistemi tolemaico e copernicano de Galileo Galilei, Le mie prigioni de Silvio Pellico, a Commedia, Tragedie e poesie de Alessandro Manzoni, Torquato Tasso (Gerusalemme liberata) e o próprio Giacomo Leopardi com Opuscules et pensées e Poesie.

Vale a pena citar, como ponto de partida, alguns versos do canto VI do Purgatorio de Dante, que se seguem à apresentação de Sordello, trovador natural de Mântua como Virgílio, guia na Commedia. O encontro entre os dois poetas da mesma cidade gera em Dante uma reflexão sobre o significado de pátria e de união, em antítese com a situação de Florença e da Itália, à época:

Ahi serva Italia, di dolore ostello, nave sanza nocchiere in gran tempesta, non donna di provincie, ma bordello!

(Purg. 6,76-78)

$\mathrm{O}$ canto, cujas personagens são almas arrependidas à beira da morte, põe em cena as divisões políticas do tempo de Dante, juntamente com alguns dos seus protagonistas. A própria narração dantesca é uma alegoria das fracturas existentes em Florença, em Itália e no Império, e começa por um elenco das mortes violentas e das vítimas de vinganças fratricidas como l'Aretin, Ghino di Tacco, Federigo Novello, Pier da la Broccia, la donna di Brabante. Todos eles abrem a digressão política do Purgatorio e são um paradigma dos ódios que abrangiam grandes e pequenas cidades medievais. À semelhança do que acontece no Inferno ${ }^{2}$ e no Paradiso, tam-

\footnotetext{
${ }^{1}$ José Bruno Carreiro, "Indículo da Livraria de Antero de Quental", Antero de Quental. Subsídios para a sua biografia, Braga, ICPD/Pax, 1981, 2. a ed., pp. 347-372.

2 "Voi cittadini mi chiamaste Ciacco" (Inf. 6, 52). No Inferno, o protagonista do canto VI é um tal Ciacco, que muitos comentadores identificam com o poeta Ciacco dall'Anguillara que fala nas divisões da cidade de Florença, e prevê a condição do
} 
bém no sexto canto do Purgatorio assistimos a um desabafo político que ficará como uma das maiores críticas de Dante à sociedade do seu tempo. Ora, se os ideais de Dante não podem ser aproximados aos da geração do Risorgimento, embora esta admirasse grandemente o significado do canto, é inegável que o autor da Commedia atribuíu uma enorme importância à Itália como nação. Quando o olhar da personagem Dante deixa espaço ao do poeta, as suas palavras referem-se a um pais pobre e abandonado a si próprio (como aliás o mostra a presença de Alberto I da Áustria ${ }^{3}$ ), pois os governantes estão muito mais interessados na riqueza material do que na ordem social.

A epopeia de Garibaldi e dos Mille de Marsala parece ser o fim das perseguições, e o rei Vittorio Emanuele II será considerado na Europa como o "Cesare in la sella", cuja ausência fora sublinhada na Commedia.

Neste sentido, torna-se interessante regressar a Antero e ao papel que esta passagem da obra dantesca desempenhou na sua obra, a ponto de compor um poema intitulado Dante, Divina comédia (Purgatório, Canto VI). Na sua reflexão sobre o destino de Itália, o poeta açoriano utiliza os versos de Dante como matéria ideal do momento histórico que o país e a Europa viviam na altura em que escrevia:

Agora espreita cada um o peito

do vizinho e olha o gládio:

e os que estreita no cinto o mesmo muro

e o mesmo fosso... comem-se! l $^{4}$

exilado Dante. No Paradiso, será Justiniano, imperador de Bizâncio, o símbolo, nesse caso ideal, do Império.

3 "O Alberto tedesco ch'abbandoni/ costei ch'è fatta indomita e selvaggia" (Purg. 6, 97). Trata-se de Alberto I de Áustria, o filho de Rodolfo de Habsburgo que foi proclamado imperador em 1298. Ambos, Alberto e Rodolfo, têm, na ideia de Dante, a culpa de ignorar as coisas italianas.

${ }^{4}$ Antero de Quental, Poesia completa (1842-1891), ed. Fernando Pinto do Amaral, Lisboa, Dom Quixote, 1991, p. 558. 
O céu "negro de nuvens", cujo silêncio cobre como uma ameaça o episódio do Purgatorio, é agora teatro para a justiça da palavra de Deus, opondo-se à vingança que caracterizava as vidas e os destinos das personagens do citado canto da Commedia. Lê-se, aliás, no poema À Itália, composto em 1862 e publicado póstumo por Teófilo Braga nos Raios de Extinta Luz:

A essa Itália que hoje existe segredou-lhe, enquanto opressa,

como sagrada promessa, em vez de iras da vingança estas palavras de espr'ança. ${ }^{5}$

Este poema foi lido por Fialho Machado, nesse ano, no Teatro Académico da Universidade de Coimbra, na circunstância da visita de Umberto I de Sabóia a Portugal. Esse dia é também o dia da intervenção de Antero e dos seus confrades da Sociedade do Raio, e o texto por eles apresentado, Saudação ao Príncipe Humberto, fica de facto como uma saudação simbólica, inevitável em relação a um descendente de reis liberais:

Os Estudantes da Universidade de Coimbra, filhos e netos dos heróicos defensores do Porto, saúdam, em nome da fraternidade de dois povos irmãos, o neto de Carlos Alberto: a mocidade liberal Portuguesa saúda, em nome da liberdade do mundo católico, o filho do amigo de Garibaldi, o filho de Vítor Manuel. ${ }^{6}$

Esta breve passagem ajuda-nos a perceber como Antero valoriza sobretudo a árvore genealógica do príncipe, verdadeira causa da saudação pública, que se enraíza num antepassado, Carlo Alberto, o qual, a par do Justiniano dantesco, é representante e modelo de justiça, enquanto criador de um

${ }^{5}$ Ib., pp. 561-562.

${ }^{6}$ Id., Prosas da época de Coimbra, Lisboa, Sá da Costa, 1982, pp. 141-142. 
sistema jurídico novo e moderno (o Statuto Albertino). Esse Pai da lei é também pai do "amigo de Garibaldi", Vittorio Emanuele II, que conseguiu realizar a unidade que Dante apenas pudera sonhar.

O interesse de Antero pelo destino de Itália fora já manifestado nos seus primeiros artigos - nomeadamente em Questão romana (abril de 1862) e em Defesa da Carta Encíclica de Sua Santidade Pio IX contra a chamada opinião liberal $(1865)^{7}$ - até confessar, numa carta de $1866^{8}$, o seu desejo de tomar parte nos acontecimentos italianos. Antero une os destinos de Itália e Portugal ("Uma a pátria do berço; outra a das almas" ${ }^{\text {) }}$, mas a admiração por Garibaldi e o seu povo teve também a função provocatória de despertar o dia-a-dia "sopa-vaca” português. Neste sentido, a "muita fé" manifestada para com o Príncipe de Sabóia pode ser lida como programa de apoio a um possível equilíbrio entre Estado e Igreja (os "dois sóis" da Monarchia de Dante), que poderia incentivar a realização do ideal romântico de paz e de união dos povos europeus. Mas Antero é sobretudo admirador da cultura, da língua e das letras italianas, como evidenciam as numerosas referências ao longo de toda a sua obra. O amor a Dante é abertamente declarado, sendo, aliás, um dos escritores que mais cita, como o mostram as várias epígrafes e referências, para além de títulos como Beatrice. A Dante Alighieri, estão obviamente também ligados alguns poemas, entre os quais Na primeira página do "Inferno" de Dante, Divina comédia, e o já citado Purgatório, Canto VI. Pelo contrário, para evidenciar a atenção dedicada a um poeta como Giacomo Leopardi, será

${ }^{7}$ Antero de Quental, Prosas, Coimbra, Imprensa da Universidade/Lisboa, Couto Martins, vol. 1, 1923, pp. 156-158 e 279-303.

8 "Sabes do que vai por Itália, e dos alistamentos de voluntários Garibaldinos. [...] Creio ser esta para nós uma boa ocasião de sairmos do absurdo sopa-vaca e arroz da vida ordinária. Queres ir?", Antero de Quental, Cartas (1852-1881), ed. Ana Maria Almeida Martins, Lisboa, UA/Comunicação, 1989, vol. I, p. 61.

${ }_{9}^{9}$ Poesia completa, p. 559. 
necessário observar para além das evidências, como o próprio Dante convida a fazer no canto IX do Inferno (também citado por Antero): ler "sotto 'l velame de li versi strani" (63).

Vale a pena lembrar que o desejo de conhecer a obra do poeta de Recanati é explicitado em diversas cartas de Antero, sobretudo nas enviadas a Joaquim de Araújo, como esta de junho de 1883:

E o Leopardi? Continuo desejoso de o conhecer. Não lhe esqueça isto. ${ }^{10}$

E acrescenta a 17 de junho: "Lembre-se de me mandar o Leopardi, com quem desejo travar mais íntimo conhecimento" ${ }^{\prime 1}$. Aliás, no seu ensaio $A$ poesia na actualidade Antero fala em Leopardi (a par de Foscolo e de outros) a propósito da subjectividade da poesia na passagem entre os séculos XVIII e XIX, sublinhando o individualismo que caracteriza toda aquela geração de poetas:

Essa poesia (signal bem claro de enfraquecimento) é toda subjectiva. É o individualismo, o egotismo que inspira nos seus grandes representantes, Byron, Shelley, Heine, Lamartine, Hugo (onde é verdadeiramente Hugo), Miczkiewicz, Espronceda, Herculano, João de Deus (que por vir tão tarde, não deixa por isso de pertencer a essa ilustre família), Leopardi, Foscolo. Elles não representam já a vida colectiva do espírito humano, a crença e as aspirações dum mundo, a apotheose gloriosa ou sombria da humanidade, que os tem por interpretes: representam-se apenas a si, elles, os ultimos duma raça condemnada a desapparecer e que, sentindo a ferida interior por onde lhes foge a vida, interrogam inquietos o horizonte e, chorando e rugindo, se assentam á beira da estrada para morrerem. ${ }^{12}$

\footnotetext{
${ }^{10}$ Cartas (1852-1881), p. 666.

${ }^{11} \mathrm{Ib}$., p. 668. Antero fala em Leopardi em mais duas cartas a Joaquim de Araújo, uma de 7-8-1883 e a outra de 10-8-1888.

${ }^{12}$ Antero de Quental, A poesia na actualidade, Lisboa, Fenda, 1988, pp. 23-24.
} 
Mas o que liga Antero a Leopardi, além de uma sintonia directa $^{13}$, é a intensidade espiritual de dois sofrimentos semelhantes, embora as respostas a tal "naufrágio na dor" sejam muitas vezes incongruentes ou até opostas nos dois poetas. A reflexão acerca da morte em relação com o amor, acerca da doença e do inexplicável significado do nascimento, o silêncio dos Deuses, a indiferença da Natureza, o mal cósmico de Leopardi não podiam deixar de gerar, em Antero, aquele desejo "de íntimo conhecimento", como uma velada presença, pelo menos desde a década de oitenta do século XIX. Na intimidade da reflexão, elabora uma filosofia pessimista que o liga ao destino de Leopardi, poeta da história e espírito romântico que alimenta e impulsiona a alma pós-romântica de Antero. Até o médico Sousa Martins, autor de uma "Nosographia de Anthero"14, aproxima os dois escritores, a partir da presumida degenerescência que eles teriam manifestado em vida:

Leopardi, por exemplo, era um degenerado. Com Anthero teve elle mais um ponto de contacto. A ambos adviera por herança a degenerescencia; ambos tiveram a psycopathia da duvida; Leopardi namorou-se da Morte e traduziu esse sentimento em palavras, que se diriam copiadas por Anthero: já considerando-a "irmã do Amor", já invocando-a como "bella e misericordiosa.". Não foi suicida o desventuroso Giacomo; todavia por mais de uma vez se surprehendeu, debruçado n'uma cisterna, a perguntar a si mesmo se deveria precipitar-se n'ella, e é de crer que, se um hydropericardio, a meu ver de procedencia brightica, lhe não houvesse encurtado tão precocemente a existencia, esta teria encontrado em qualquer bala de revolver o seu ponto final. Vagabon-

${ }^{13}$ Luciana Stegagno Picchio evidencia o itinerário italiano de Antero que se inicia com Dante e passa por Francisco de Assis e Leopardi, em "Italie mythique d'Antero de Quental. De Garibaldi à St. François d'Assise”, in Antero de Quental et l'Europe. Actes $d u$ Colloque (Paris, 13-14 Juin 1991), Paris, FCG, 1993, pp. 147-158.

${ }_{14}$ Trabalho aliás baseado em dados pouco atendíveis, como foi demostrado por Ana Maria Almeida Martins em Antero de Quental e a génese do "In Memoriam", Angra do Heroísmo, DRC, 2001. 
dou pelo mundo fora, ainda mais do que Anthero. Eram cerebraes anteriores um e o outro; ambos cultivaram a mesma forma amorosa, enervante para o individuo, esterilisante para a espécie; e de Leopardi chegou a dizer-se que morreu virgem, como Newton - outro genial nevropatha. A desillusão traduziram-n'a os dois poetas em amarissimas ironias. ${ }^{15}$

2. O reino da lua, que Ariosto imaginava repleto de todas as virtudes humanas perdidas, é desde sempre um ponto de referência privilegiado no diálogo entre poeta e Natureza. Mas, enquanto a lua ariostesca era lugar de acontecimentos fantásticos, onde se devia buscar o juízo perdido de Orlando, o poeta da época romântica olha para ela procurando respostas que não lhe pode ou quer dar, tornando alegoricamente manifesto o seu silêncio.

Além do mais, se a lua de Antero é essencialmente consoladora, a do poeta italiano está sujeita a perguntas implícitas ou explícitas da Terra e do Homem, e encontra-se alheada de todos os significados que lhe foram sendo atribuídos. A lua de Giacomo Leopardi tem um papel semelhante ao de um intermediário. A sua presença é evidente sobretudo se pensarmos que observa o céu para encontrar uma não-relação, uma diferença que impede o homem de imaginar uma lógica. A ideia de um cosmos como espelho da História, por exemplo, desaparece de vez no Dialogo della Terra e della Luna, onde a lua, apesar da sua natureza silenciosa, permite à Terra fazer perguntas:

Se ti pare di favellarmi, favellami a tuo piacere; che quantunque amica del silenzio, come credo e tu sappi, io t’ascolterò e ti risponderò volentieri, per farti servigio. ${ }^{16}$

${ }^{15}$ J. Sousa Martins, "Nosographia de Anthero", in In Memoriam. Anthero de Quental, Porto, Mathieu Lugan, 1896, p. 284-285.

${ }^{16}$ Giacomo Leopardi, Poesie e prose, Milano, Mondadori, 1988, vol. II, p. 46. 
Todavia, a Terra não se mostra capaz de elaborar nada de interessante e a lua permanece distante, inacessível, indiferente a pedidos tão banais, pois estes reflectem as interrogações dos seres humanos. Sendo que tudo está destinado "infaticabilmente alla morte, con sollecitudine e celerità mirabile ${ }^{17}$ ", como se lê no Cantico del Gallo Silvestre, também a lua, alheia aos homens, permanece imutável, mesmo porque o mal é constante e essencial, e a Natureza não permite ser desvendada. A necessidade de saber está destinada ao fracasso da interrogação a um céu mudo. $O$ próprio nascimento é a primeira fonte de dor e a morte é o fim das dores. Na verdade, um dos pontos de contacto entre Leopardi e Antero reside nesta tentativa de concentrar simbolicamente no momento do nascimento o princípio da dor. Escreve Antero no poema A Germano Meireles:

Quem fora tão ditoso que olvidasse...

Mas nem seu mal com ele então dormira,

que sempre o mal pior é ter nascido! ${ }^{18}$

Palavras semelhantes ${ }^{19}$ são utilizadas pelo poeta italiano no último verso de Canto notturno di un pastore errante dell'Asia:

È funesto a chi nasce il dì natale. ${ }^{20}$

E no Ultimo canto di Saffo:

${ }^{17}$ Ib., p. 164.

${ }^{18}$ Antero de Quental, Poesia completa (1842-1891), pp. 227-228.

${ }^{19}$ Que ecoam Lucrécio, "cum primum luminis oras/ nixibus ex alvo matris natura profundit/ vagituque locum lugubri complet, ut aequumst/cui tantum in vita restet transire malorum", De Rer., 5,222-227.

${ }^{20}$ Giacomo Leopardi, Canti, ed. Giorgio Ficara, Milano, Mondadori, 1987, p. 170. E acrescenta o pastor: "Nasce l'uomo a fatica,/ ed è rischio di morte il nascimento./ Prova pena e tormento/ per prima cosa; e in sul principio stesso/ la madre e il genitore/ il prende a consolar dell'esser nato", p. 166. 
[...] Arcano è tutto,

fuor che il nostro dolor. Negletta prole

nascemmo al pianto, e la ragione in grembo

de' celesti si posa. ${ }^{21}$

A desesperada interrogação do pastor de Leopardi espelha uma repetição sem sentido e a vaidade de todas as coisas, por isso o pastor lhe dirige as suas perguntas:

Che fai tu, luna, in ciel? Dimmi, che fai, silenziosa luna?22

Os caminhos da lua e do pastor correm paralelos um ao outro, testemunhando a falta de sentido de duas existências colocadas num deserto sem respostas. Mas enquanto a lua continua "contemplando i deserti", o pastor interroga-se acerca do destino dela: "Ancor non sei tu paga di riandar/ di riandare i sempiterni calli?/ Ancor non prendi a schivo, ancor sei vaga/ di mirar queste valli?/ Somiglia alla tua vita/ la vita del pastore"23.

Toda a imagem é marcada por uma impressão de ausência, pelo vazio nocturno em que só a voz do pastor se ouve, invejoso da condição inocente e inconsciente do seu rebanho ${ }^{24}$. Mas, apesar da ausência de um sinal que trouxesse um significado, o pastor leopardiano é ainda capaz de olhar para a lua como se esperasse alguma coisa, como se além desta falta de sentido a sua simples existência tivesse o poder de consolar. A "graziosa luna" ${ }^{25}$ do poema Alla luna é a destinatária privilegiada das palavras do sujeito poético, do seu testemunho

${ }^{21} \mathrm{Ib}$., p. 101.

${ }^{22} I b .$, p. 164 .

${ }^{23} \mathrm{Ib}$.

${ }^{24}$ Cfr. Giorgio Ficara, Il punto di vista della natura. Saggio su Leopardi, Genova, Il Melangolo, 1996, pp. 91-114.

${ }^{25}$ Giacomo Leopardi, Canti, p. 116 
da dor e da passagem do tempo. A dor da juventude tinha a ilusão, agora perdida, do futuro, e a lua, confidente que tudo sabe e nada diz, é uma observadora desinteressada desta passagem inexorável: "E tu pendevi allor su questa selva/ siccome or fai, che tutta la rischiari" ${ }^{26}$. Todavia, ela concede ao sujeito a sensação de que pode compreender e entender as suas perguntas: "Pur tu, solinga, eterna peregrina,/ che sì pensosa sei, / tu forse intendi,/ questo viver terreno,/ il patir nostro, il sospirar, che sia" ${ }^{\prime 2}$.

Se considerarmos agora os versos de Ao luar, reparamos que a lua é tratada com palavras afectuosas, considerada uma irmã, cujo curso no céu é associado ao percurso do sujeito, tal como Leopardi havia feito com o seu pastor ("Somiglia alla tua vita/ la vita del pastore"):

O céu, o céu é tão grande!

O peito é tão solitário!

Assim é que vamos ambos,

cada qual com seu fadário! ${ }^{28}$

Essa comunhão de destinos é também visível em Per amica silentia lune, também encimado por uma epígrafe da Commedia ("Guardai in alto..."). Aqui a lua, que surge "detrás da montanha, saudosa/ como a virgem dos sonhos" 29 , é silenciosa, mas sobretudo uma amiga que se torna consolação para o sofrimento. A sua aparição é sossego e o olhar para o céu contém uma interrogação parecida com a do sujeito leopardiano:

A viagem não teme, antes anseia, quebrada a forma deste ser, alar-se

\footnotetext{
${ }^{26} \mathrm{Ib}$.

${ }^{27} \mathrm{Ib}$., p. 167.

${ }^{28}$ Antero de Quental, Poesia completa, p. 136.

${ }^{29}$ Ib., p. 532.
} 
em busca de outra mais perfeita, e sempre de degrau em degrau, de esfera em esfera, - metempsicose eterna!- sublimar-se na progressão deste ascender constante da parte ao todo, do mortal princípio em busca de um futuro inatingível. ${ }^{30}$

Na visão de Antero, é possível um além por trás do silêncio do universo e na metafísica pode encontrar-se uma consolação parcial. Ao invés, em Leopardi já não existe maneira de fugir, e nem sequer um lugar em que o sujeito se possa considerar irmão do Universo. A lua, tal como o céu e tudo o que pertence à Natureza, sabe o que o homem não sabe e existe para além da existência mortal. Ela é uma interlocutora de eleição e o "peregrinar constante/ a entrevista do infinito e do homem", no poema de Antero, não pode deixar de nos lembrar versos de La vita solitaria, cuja última parte é mais uma invocação à rainha da noite. A sua luz penetra na cidade, nos campos e nas actividades nocturnas e, apesar da sua distância e mudez, consegue ser porto de abrigo para o poeta:

A me sempre benigno il tuo cospetto sarà per queste piagge, ove non altro che lieti colli e spaziosi campi m’aprì la vista ${ }^{31}$

Tal como acontecia no Canto notturno, a lua torna-se espelho da existência humana em Il tramonto della luna. Com efeito, estabelece-se aqui um procedimento analógico mais directo. O desaparecimento da lua, além de ser um ocaso que faz empalidecer o mundo ("Scende la luna; e si scolora il mondo;/ spariscon l'ombre, ed una/ oscurità la valle e il

\footnotetext{
${ }^{30} I b .$, p. 536.

${ }^{31}$ Giacomo Leopardi, Canti, pp. 126-127.
} 
monte imbruna;/ orba la notte resta"32), é associado ao percurso existencial dos homens, cuja vida, após as ilusōes da juventude, empalidece como uma noite sem lua:

Tal si dilegua, e tale

lascia l'età mortale

la giovinezza. In fuga

van l'ombre e le sembianze

dei dilettosi inganni; e vengon meno

le lontane speranze,

ove s'appoggia la mortal natura.

Abbandonata, oscura

resta la vita. ${ }^{33}$

É importante observar como o paralelo directo com os elementos da Natureza é utilizado por Leopardi em La ginestra $o$ il fiore del deserto, considerado o seu testamento espiritual. A ampla descrição da força cega e destruidora da Natureza, que abre o poema, revela a falta de esperança própria do pensamento de Leopardi, já visível na escolha da epígrafe do Evangelho de São João: "E gli uomini vollero piuttosto le tenebre che la luce". Não se trata de uma condenação arbitrária da Natureza (que ignora o homem), diz-nos Leopardi, mas de uma dupla condenação. Além da indiferença do universo, o ser humano, ao contrário da humilde giesta, não sabe aceitar a sua ignorância e a sua impotência (e é o próprio pensamento, na sua acepção mais alta, o responsável por esta $\left.\operatorname{derrota}^{34}\right)$ e por isso a sua história, a História, é um elenco de desgraças. Neste sentido, tem traços semelhantes aos versos de Mais luz! ("Tu, lua, com teus raios vaporosos,/ cobre-os, tapa-os, e torna-os insensíveis" ${ }^{35}$ ), em que Antero apresenta

${ }^{32}$ Ib., p. 218.

${ }^{33} I b .$, p. 219.

34 "Vuoi di nuovo il pensiero/ sol per cui risorgemmo/ dalla barbarie in parte, e per cui solo/ si cresce in civiltà, che sola in meglio/ guida i pubblici fati”, ib., p. 224.

${ }^{35}$ Antero de Quental, Poesia completa, p. 399. 
uma lua que existe apenas como antítese do sol. A sua luz é farol da vida nocturna a iluminar "abismos rumorosos". Aqui, o eu poético ainda consegue ver parcialmente um sol e, sobretudo, um infinito, que para o último Leopardi existia apenas como não ser, como destino final, inútil e sem surpresas, tal como tudo o resto.

Elena Losada Soler ${ }^{36}$ observa que Antero tentou povoar o seu deserto em primeiro lugar com o amor, criando a imagem de uma mulher que é fonte de descanso, associada à figura da mulher-mãe, e depois com a exaltação da morte como porta do Infinito. Leopardi não deixa espaço a nenhuma consolação, sendo o amor leopardiano estranho ao amor que normalmente conhecemos. Mesmo a canção Alla sua donna mostra o modo como o poeta de Recanati trata o assunto e como a sua ideia de amor pode apenas ser associada à ideia de beleza, como hino a uma mulher que é de facto beleza longínqua, lembrando a lírica provençal: "Cara beltà che amore/ lunge m'ispiri [...]"37, mas de uma inspiração que nunca pode afastar a ausência absoluta de esperança: "Nulla spene m’avanza" 38 . E também o célebre $A$ Silvia põe em cena, não um amor real, mas o fascínio das coisas que nascem para desaparecerem. Além das luminosas imagens de um tempo perdido, o poema é canto de destruição, fim irreparável, sombra de morte que repropóe a falta de um sentido:

Questo è quel mondo? questi

i diletti, l'amor, l'opre, gli eventi

onde cotanto ragionammo insieme?

Questa è la sorte dell'umane genti? ${ }^{39}$

${ }^{36}$ Elena Losada Soler, "Antero e Leopardi. O naufrágio na dor", in Antero de Quental e o destino de uma geração. Actas do colóquio internacional no centenário da sua morte, ed. Isabel Pires de Lima, Porto, Asa, 1991, pp. 343-349.

${ }^{37}$ Giacomo Leopardi, Canti, p. 134

${ }^{38} \mathrm{Ib}$., p. 135.

${ }^{39} I b .$, p. 154. 
Em Mors-amor, Antero deixa em aberto a luta entre duas forças da mesma intensidade (amor e morte, como em Leopardi), representadas por uma "fera estranha" e um "cavaleiro potente" ${ }^{40}$, dignos de igual devoção. A morte tem um papel consolatório, para além de iniciático ("Morrer é ser iniciado"), como podemos observar sobretudo no Elogio da morte, baseado na dimensão mística que determina a libertação de todo o mal e, finalmente, o encontro com a verdade ("Morte! irmã do Amor e da Verdade" ${ }^{41}$ ). Se a vida é dor, o seu fim deve ser de certa maneira uma consolação, independentemente do sentido que ambos os poetas atribuem ao momento da morte. Por isso, se pesquisarmos uma vez mais a sua produção literária, encontramos constantes alusōes a este aspecto paralelo. Lemos no citado Elogio da morte:

Muitas vezes é certo, na canseira, no tédio extremo dum viver magoado, para ti levantei o olhar turbado, invocando-te, amiga derradeira... ${ }^{42}$

E escreve Leopardi em Amore e morte, acerca da beleza da morte:

Bellissima fanciulla, dolce a veder, non quale la si dipinge la codarda gente ${ }^{43}$

Lê-se, aliás, no poema Le ricordanze:

Questa mia vita dolorosa e nuda Volentier con la morte avrei cangiato. ${ }^{44}$

\footnotetext{
${ }^{40}$ Antero de Quental, Poesia completa, p. 279.

${ }^{41}$ Ib., p. 301.

${ }^{42} \mathrm{Ib}$.

${ }^{43}$ Giacomo Leopardi, Canti, p. 184.

${ }^{44}$ Ib., p. 157.
} 
É claro que o sofrimento físico - por um lado a deformidade e os problemas de visão do poeta italiano e por outro a doença de Antero - acrescenta essa visão da morte libertadora que as respectivas obras mostram. Leopardi e Antero chegaram ambos (como se confirma nas cartas e nos apontamentos íntimos) a considerar a doença física mais insuportável do que as dores espirituais. Embora não tenha cometido suicídio, o poeta italiano, no Zibaldone e em outros momentos da sua obra, faz referências explícitas ao suicídio, não como acto de renúncia, mas como afirmação da liberdade humana. O símbolo deste gesto é Bruto, cuja derrota determina o fim da Roma heróica e, para Leopardi, o desaparecimento da antiguidade mítica. Nada fica, senão, para além de qualquer significado ético-político, o drama de um herói vencido perante a vida e que só tem consolação na morte, como já acontecera em Dialogo di Plotino e Porfirio ${ }^{45}$. Mas se no diálogo estão presentes duas forças em oposição, a de Plotino que tenta convencer o amigo a não pôr em prática a sua intenção de morte, e a firmeza de Porfirio, o momento de Bruto "fermo già di morir" ${ }^{\prime 4}$ é o momento da tragédia sem remédio nem discussão.

O suicídio, diz Leopardi, não é inatural até porque a própria vida é inatural e, assim, o propósito da personagem de Bruto minore não pode ser de todo condenável. As suas perguntas extremas, na "sonnolenta aura" da noite, conduzem-nos, uma vez mais, à indiferença persistente da Natureza, imutável também ela neste momento maximamente trágico. O grito desesperado de Bruto dirigido à lua que surge calma (“Tu sí placida sei?”) é ainda desejo de saber, de conhecer, de pesquisar no mundo criado para procurar, imediatamente antes de morrer, a resposta para um silêncio inexplicável.

\footnotetext{
${ }^{45}$ Ib., vol. II, pp. 195-208.

${ }^{46} \mathrm{Ib}$., vol. I, p. 29.
} 